\title{
Managing for Joint Outcomes - the breakthrough from the front line
}

\author{
Derek Gill, Elizabeth Eppel, Miriam Lips and Bill Ryan
}

\begin{abstract}
Politics is a strong and slow boring of hard boards. It takes both passion and perspective. ... man would not have attained the possible unless time and again he had reached out for the impossible. But to do that a man must be a leader, and not only a leader but a hero as well, in a very sober sense of the word. (Max Weber, Politics as Vocation, 1965, p.54)
\end{abstract}

Moving from planning for outcomes through formal accountability documents such as Statements of Intent to actually managing for outcomes is a difficult challenge - the 'reach for the impossible', in Weber's words. But it is an important challenge if we are to achieve the goal of 'a world class system of professional State Services serving the government of the day and meeting the needs of New Zealanders. ${ }^{1}$ One way to progress managing for outcomes is through top-down approaches, reflected in the central agency guidance, Getting Better at Managing for Shared Outcomes.

An alternative approach - which is the one adopted here - is to take the 'worm's eye' view from the front line, not the 'bird's eye' view. This article summarises some of the initial questions prompted by the Emerging Issues Project (EIP) on public management which Public Service Chief Executives have commissioned from Victoria University of Wellington. This project is focused on three research questions:

- What are the preconditions for more joined-up user/ citizen-centred services?

- What are the characteristics of policy areas where more joined-up user/citizen-centred services are found in New Zealand?

- What helps and what hinders the diffusion of more joined-up approaches to user/citizen-centred services?

The view from the front line provides a quite different perspective from the view from central agencies or from departmental head offices in Wellington. This is well documented in the literature on service delivery, starting with Pressman and Wildavsky (1973) and leading to Lipsky's (1980) 'street-level bureaucrats', the most cited example of this approach. The last three decades of implementation research illustrate that managing for outcomes from the street-level or front-line perspective requires balancing contradictions such as those of 'passion' and 'perspective', which Weber highlighted (in the quote above).

\section{The view from the front line}

To understand the front-line perspective, staff from Victoria University are undertaking intensive interviews with workers involved in a range of examples of joined-up ways of working. ${ }^{2}$ One case looks at the response of staff in a number of agencies to two whanau in south Auckland which had experienced a series of youth suicides.

'Everyone in this room is talking crap', commented a whanau representative, having listened for an hour to staff from a range of government agencies talking about what services they could provide to the whanau. The breakthrough moment came when the staff realised they had to work differently; it was not about packaging up existing services for the whanau. Their system perspective, their pre-existing silos, categories and management practices, simply didn't align with the real-world lives and needs of the people they were dealing with. It was these that needed to change, not just the clients. Things had to be turned the other way

1 The State Services Commission's overall state services goal is further articulated in six development goals, including 'coordinated state agencies ensuring that the total contribution of government agencies is greater than the sum of its parts'.

2 The examples include a range of sectors: autism, integrated case management in the social sector, recognised seasonal employer scheme in the labour market, South Auckland schools, the Mayors Task Force for Jobs, and the National Maritime Coordination Centre. 
round - it was about working with whanau, building on their strengths to work out what services they needed (Schwass, 2007, p.1).

Parenting children with disabilities such as autism is a difficult journey. In addition to the challenge of parenting and keeping other family relationships intact, it also involves navigating through a range of government-sponsored service provision agencies, including Needs Assessment Service Coordinators (NASCs), Group Special Education of the Ministry of Education, Work and Income, social workers from District Health Boards and social service agencies, and sometimes Child Youth and Family (CYF). Each has their own process and criteria. Most staff do the job to the best of their ability, treating each case on its merits to ensure that families receive their entitlement. But some staff define their role as acting as brokers and facilitators to join up access to services. The breakthrough comes when they cease to see the client as a case and focus on the holistic needs of the individual person.

The stories of staff acting 'as leaders and heroes' to make the system work are encouraging. Actions of individual staff to make what is necessary happen can ensure that outcomes meaningful to the client are achieved. Isolated individuals acting on their own will not be enough to achieve systematic change. In fact, no particular understanding or appreciation exists of the work of these 'public entrepreneurs'. As a result, this research is focused on the preconditions, enablers and keys to success for this cross-agency way of working. The particular concern is to focus on services reconfigured to what New Zealanders really need. It is also focused on identifying potential 'show stoppers' and 'derailers', and the keys to success that characterise this way of working.

Inter-agency working covers a range of activities and

\section{Figure 1: Continuum of joined-upness}

\section{Fully Focused}

\section{Co-operation}

Co-ordination

Limited

connection

Medium

Low intensity connections

Medium intensity
Fully Connected

\section{Collaboration}

High

connection

High intensity there is no lingua franca or accepted definitions for the various multi-party arrangements that exist. This article will follow Keast $\&$ Brown (2007) in distinguishing a continuum of the 'three Cs', ranging from co-operation to co-ordination and collaboration. While these terms are often used interchangeably, the three Cs are not the same.

Co-operation is conceptualised as the starting or base level of inter-organisational relationships: 'merely the task of getting along with others so that you could both achieve your own goals'.

Co-ordination has an instrumental function involving processes requiring organisations to work together. Participating in co-ordination does not require loss of individual member autonomy. Co-ordination represents an efficient way of driving through goals and undertaking joint tasks.

Collaboration moves beyond the instrumental processes of co-ordination to find 'ways to work better together' and achieve greater efficiencies and scale of outcome. Collaboration is seen as a more intensive process. It involves processes to get to a position of trust and shared understandings of language, values and goals. Collaboration is more likely to lead to new ways of working and innovation.

This article focuses on the most intensive or collaborative end of the spectrum. Collaboration is a far more radical activity than co-operation. It involves seeing the world from a new perspective, one which starts with outcomes, works backwards in terms of 'what's therefore needed', and then redefines what providers and agencies need to do - a radical shift which usually seems to require a 'magic moment' of recognition of failure before it can occur. This usually involves an inversion of meaning which redefines what was once taken as normal to be problematic, sometimes coming from the client, sometimes from the staff. Almost all of the case studies being reviewed have these characteristics.

The international literature ${ }^{3}$ suggests that collaborative approaches are more likely to form when there is growing turbulence in the external environment and there is a growing realisation that 'we can't do it on our own'. Groups, once formed, are more likely to succeed when

3 See the literature review by Elizabeth Eppel (2007, available on request) and in particular Bryson, Crosby \& Middleton Stone (2006). 
there are already in existence linking mechanisms, such as existing networks and shared understandings about competing mental models and meanings of key words.

Quality process is also emerging as important both in the literature and in specific examples being reviewed as case studies. In particular, joint working groups are more likely to succeed when conflict is managed and power imbalances reduced, and trust is built, providing both the lubrication and the glue. One factor featuring strongly is the role of leadership by 'public entrepreneurs', while in some, but not all, examples, leadership by committed sponsors and effective champions is also important.

Interestingly, the international literature identifies formal agreements such as plans and memoranda of understanding as important for success, but this is not coming through as important in the dialogue with practioners in New Zealand, where practice relies heavily on informality. Similarly, there are different experiences of whether inputs, processes and outcomes need to be closely tracked. One open question is whether decentralised and more or less self-governing networks are more effective than inter-agency groups centralised around a lead agency.

One key conclusion to emerge repeatedly, both in New Zealand and overseas, is that success is difficult. Working jointly is hard and it takes energy and commitment. It involves working on the edge and taking managed risks.

This raises the question of when are more collaborative services likely to emerge?

A number of sources have noted the need to be clear about the perceived problem to which horizontal coordination and integration are seen as solutions.

Interestingly, Perri 6 (2004) suggests that the challenge is not in the specialisation of each agency. It is more likely to be in the fragmentation of how each organisation sees the issue and responds to it; lack of good conflict management; or inadequately structured relationships between specialties. The rhetoric often used of 'overcoming barriers' or 'breaking down boundaries' is often misleading. Rather, collaboration is about attempts to put boundaries in different places and to create 'border crossings' suitable for particular vehicles.

The next phase of the EIP project is to test how important the factors identified by the international literature and New Zealand examples are. A number of early ideas are emerging:

Role for public entrepreneurs. Entrepreneurship in the public sector is not an oxymoron. Public entrepreneurs defined their role to include keeping the flame alive and driving through to achieve success, sometimes at personal cost in terms of time, career and reputation. They exhibited a passion to make a difference. Some take comfort that 'no-one ever got fired for doing the right thing'.

The importance of mental models. Staff start in different places with different views about their roles, different ideas of what is important, and sometimes completely different meanings for key shared terms. Over time a quality process leads to shared understanding of these differences. Often the breakthrough comes when they cease to see the client as a case and focus on the holistic needs of the individual person.

Making the formal system work. Front-line staff report making the system work, managing within the formal system by coming up with a way to work around, and working up to and testing the boundaries of the formal system without explicitly breaking formal rules.

Multiple accountabilities. Front-line staff report a strong sense of loyalty and responsibility to their colleagues in their network and to the client or service user. They manage in multiple worlds, balancing their horizontal responsibilities with their formal accountability upwards within the organisation. Often this formal accountability is seen as secondary and is just part of the formal system to be managed.

Rules versus discretion. Some staff work in a high-trust, high-discretion environment, others in a lowerdiscretion environment. Even those with lower formal discretion exercise judgement about which rules to enforce in a particular context. What is common is that the job was defined as being about achieving the best outcome for the client or service user.

The paradox of authority. To be effective, staff in a network need 'soft' power or authority (access to resources, ability to commit to actions), but use of hard power, such as sanctions and threats, is often counterproductive. 


\section{Conclusion}

There are a number of factors driving new ways of working to deliver public services. From the top down there has been a shift in emphasis in the formal public management system from the managing of outputs to managing for outcomes. In turn, this shifts the focus from efficiency (how can we deliver our services better) to effectiveness (what services do we deliver and how can we work with others on this). From a bottom-up, street-level staff perspective, all the examples show a passion to make a difference for clients almost regardless of the formal public management system. Other contextual factors include the nature of 'wicked' issues, where outcomes are co-produced and these cannot be addressed effectively through traditional bureaucratic service delivery. Another factor again is a decline of trust in the 'professionals know best' maxim and increased expectations of citizens of the quality of service delivery. We live in a world where, increasingly, power is shared and in which many groups are involved in acting on public challenges.

The relative importance of these factors in New Zealand is being examined in the next phase of the EIP project, once the data gathering has been completed. We will report further in Policy Quarterly in 2008 on what we found. In the interim, if you want to know more about the project or have something to offer, contact derek. gill@vuw.ac.nz.

\section{References}

6, P. (2004) 'Joined-up government in the Western world in comparative perspective: a preliminary literature review and exploration', Journal of Public Administration Research and Theory, 14 (1), pp.103-38

Bryson, J.M., B.C. Crosby \& M. Middleton Stone (2006) 'The design and implementation of cross-sector collaborations: propositions from the literature', Public Administration Review (special issue), pp.44-5

Department of Prime Minister and Cabinet, State Services Commission, Te Puni Kokiri \& The Treasury (2004) Getting Better at Managing for Shared Outcomes, www.ssc.govt.nz/display/document.asp?docid=4126

Eppel, E. (2007) 'Integrated government services: literature review', unpublished

Gray, A. (2002) 'Integrated service delivery and regional co-ordination: a literature review', Wellington: State Servcices Commission

Krest, R. \& K. Brown (2007) 'Getting the right mix: unpacking integration meanings and strategies', International Public Management Journal, 10 (1), pp.9-33

Kickert, W.J.M., E.-H. Klijn \& J.F.M. Hoppenjam (eds) (1997) Managing Complex Networks: strategies for the public sector, London, Thousand Oaks, New Delhi: Sage Publications

Lipsky, M. (1980) Street-level Bureaucracy: dilemmas of the individual in public services, New York: Russell Sage Foundation

Pressman, J. \& A. Wildavsky (1973) Implementation: how great expectations in Washington are dashed in Oakland; or, why it's amazing that Federal programs work at all, this being the saga of the Economic Development Administration as told by two sympathetic observers who seek to build morals on a foundation of ruined hopes, Berkeley: University of California Press

Schwass, M. (2007) 'Responding to a call for helpcoordinated case management in Papakura', Australia and New Zealand School of Government case pgraramme $2007-73.2$

State Services Commission (2006) 'Development goals', http://ssc.govt.nz/display/document.asp?navid $=242$

Weber, M. (1965) Politics as Vocation, Philadelphia: Fortress Press 